\title{
Age-related declines in a two-day reference memory task are associated with changes in NMDA receptor subunits in mice Kathy R Magnusson*1,2,3, Brandi Scruggs ${ }^{3,4}$, Xue Zhao ${ }^{1,2}$ and Rebecca Hammersmark ${ }^{2}$
}

\begin{abstract}
Address: ${ }^{1}$ Department of Biomedical Sciences, College of Veterinary Medicine, Oregon State University, Corvallis, OR, 97331, USA, ${ }^{2}$ Department of Biological Sciences, University of Idaho, College of Science, Moscow, ID, 83844, USA, ${ }^{3}$ Behavioral testing performed at: Department of Biomedical Sciences, College of Veterinary Medicine and Biomedical Sciences, Program in Molecular, Cellular, and Integrative Neurosciences and Department of Psychology, Colorado State University, Fort Collins, CO, 80523, USA and ${ }^{4}$ Department of Psychology, Worcester State College, Worcester, MA 01602-2597, USA
\end{abstract}

Email: Kathy R Magnusson* - Kathy.Magnusson@oregonstate.edu; Brandi Scruggs - bscruggs@worcester.edu; Xue Zhao -xuezhao@uidaho.edu; Rebecca Hammersmark - rhammers@uidaho.edu

* Corresponding author

Published: 22 June 2007

BMC Neuroscience 2007, 8:43 doi:10.1/86/147|-2202-8-43
Received: 3I August 2006

Accepted: 22 June 2007

This article is available from: http://www.biomedcentral.com/I47I-2202/8/43

(C) 2007 Magnusson et al; licensee BioMed Central Ltd.

This is an Open Access article distributed under the terms of the Creative Commons Attribution License (http://creativecommons.org/licenses/by/2.0), which permits unrestricted use, distribution, and reproduction in any medium, provided the original work is properly cited.

\begin{abstract}
Background: C57BL/6 mice show a relationship during aging between NMDA receptor expression and spatial reference memory performance in a 12-day task. The present study was designed to determine if age-related deficits could be detected with a shorter testing protocol and whether these deficits showed a relationship with NMDA receptors. Mice were trained in a reference memory task for two days in a Morris water maze. Cued testing was performed either after or prior to reference memory testing. Crude synaptosomes were prepared from prefrontal/ frontal cortex and hippocampus of the mice that underwent reference memory testing first. NMDA receptor subunit and syntaxin proteins were analyzed with Western blotting.

Results: Young mice showed significant improvement in probe and place learning when reference memory testing was done prior to cued testing. A significant decrease in performance was seen between 3 and 26 months of age with the two-day reference task, regardless of whether cued testing was performed before or after reference memory testing. There was a significant decline in the protein expression of the $\varepsilon 2$ and $\zeta$ I subunits of the NMDA receptor and syntaxin in prefrontal/ frontal cortex. The subunit changes showed a significant correlation with both place and probe trial performance.

Conclusion: The presence of an age-related decline in performance of the reference memory task regardless of when the cued trials were performed suggests that the deficits were due to factors that were unique to the spatial reference memory task. These results also suggest that declines in specific NMDA receptor subunits in the synaptic pool of prefrontal/frontal brain regions contributed to these age-related problems with performing a spatial reference memory task.
\end{abstract}




\section{Background}

Memory is one of the earliest of the cognitive functions to show declines during the aging process [1]. Memory deficits associated with aging are seen in humans and nonhuman primates (see reviews [2,3]), dogs [4] and rodents [5-8]. One type of memory that is important for how individuals cope with their environment is spatial memory. Humans show $30 \%$ to $80 \%$ drops in performance in spatial memory tasks as they age [9-14]. Mice and rats also exhibit deficits in spatial memory performance during aging [6-8,15-19].

Aged C57BL/6 mice show spatial reference memory problems when tested over 12 days in the Morris water maze [17-19]. We were interested in adopting a task that would show age-related deficits in fewer days in order to test drug interventions with the use of osmotic pumps (Durect Corp., Cupertino, CA). The smallest pump available can deliver drug for 3-14 days, but, in addition to the time necessary for behavioral testing, time is also needed for recovery from surgery and pretraining. Berry and coworkers developed a one-day spatial memory task for rats, in which young rats show good improvement in performance 8 trials in one day [20]. Our initial attempts to use this one-day task with mice showed that young mice could not show a significant improvement within 8 trials in one day, but could with two days of testing (unpublished observation). The present study was designed to determine whether we could detect significant differences in performance between young and old mice in a spatial reference memory task with a two-day testing protocol (Figure 1).

The N-methyl-D-aspartate (NMDA) receptor, a subtype of glutamate receptors, is particularly important in learning and memory functions [21,22]. NMDA antagonists inhibit memory performance [23-26] and block the initiation of long-term potentiation in the hippocampus [26-

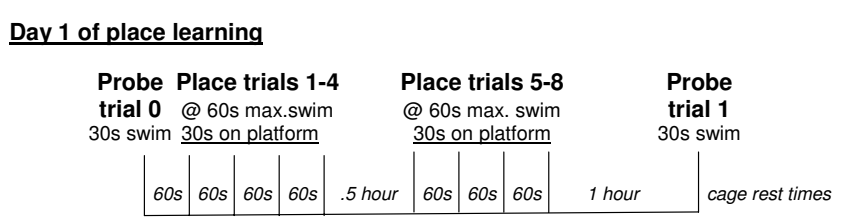

Day 2 of place learning

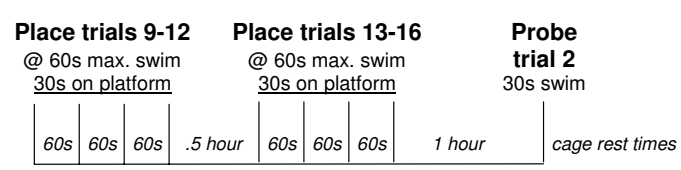

Figure I

Diagram of the protocol for reference memory testing over a two day period, including both place learning and probe trials. s, seconds; max., maximum.
28] and neocortex [29]. These studies suggest that detrimental changes to the NMDA receptor during the aging process should impact negatively on memory functions.

Aging animals do exhibit declines in NMDA receptor binding densities and functions, including memoryrelated functions. NMDA-stimulated release of transmitters is decreased with increasing age [30,31]. Long-term potentiation is also altered in aged rodents [32,33]. Agerelated declines in binding of glutamate and $[( \pm)$-2-carboxypiperazin-4-yl] propyl-1-phosphonic acid (CPP) to NMDA binding sites have been reported in mice, rats, dogs, and monkeys [34-39]. Humans also exhibit declines with increased age in binding of $\left[{ }^{3} \mathrm{H}\right] \mathrm{MK} 801$ to the NMDA receptor complex in the frontal cortex [40]. Changes in NMDA binding sites during aging have been correlated with poor performance in reference memory tasks, such as the Morris water maze, in both prefrontal/ frontal cortical regions [17] and in the hippocampus $[17,37]$.

Functional subunits of the NMDA receptor complex have been cloned for rats [41-43] and mice [44-47]. The zeta1 ( $\zeta 1$; rat NR1) subunit has the same distribution as NMDAdisplaceable $\left[{ }^{3} \mathrm{H}\right]$ glutamate binding $[41,46,48]$. The four members of the epsilon family of subunits, $\varepsilon 1-4$ (rat NR2A-D), in the mouse [44-46] each provide different agonist/antagonist affinities to $\zeta 1 / \varepsilon$ heteromeric receptors $[45,47]$. These $\varepsilon$ subunits also produce different gating behaviors, responses to $\mathrm{Mg}^{++}$, and I/V curves $[42,43]$.

There is a difference in the effects of aging on different subunits of the NMDA receptor. The density of mRNA expression for the $\varepsilon 2$ subunit declines with increasing age in the cerebral cortex and dentate gyrus of male C57BL/ 6 mice [38]. These changes in $\varepsilon 2$ mRNA expression correlate significantly with age-related changes in binding of agonist to NMDA sites both across cortical and hippocampal regions [38] and within prefrontal/frontal cortical regions [18]. There is also an overall decrease in mRNA expression of the $\zeta 1$ subunit across cortical and hippocampal regions, but to a lesser degree than seen with the $\varepsilon 2$ subunit [38]. Although age-associated changes in $\varepsilon 2$ mRNA in the prefrontal/frontal cortex correlate with changes in NMDA receptor binding and the binding correlates with spatial reference memory problems [18], there has not been a direct relationship seen between the mRNA expression of the NMDA receptor and memory performance [18]. C57BL/6 mice show significant decreases with increasing age in the protein expression of $\varepsilon 2$ and $\zeta 1$ subunits in homogenates from the whole cerebral cortex [49]. Significant declines during aging in protein expression in hippocampal homogenates are also seen in the $\zeta 1$ and $\varepsilon 2$ subunits in both mice [49] and Fisher 344 rats [50,51]. Homogenates of only prefrontal/frontal cortex show a sig- 
nificant age-related decrease in the protein expression of the $\varepsilon 2$ subunit alone [52]. Given the differences in pharmacological and electrophysiological properties that different combinations of subunits produce $[42,43,45,47]$, it is important to determine if any of these subunit changes relate to memory performance declines during aging. It seems likely that the relationship between the receptor subunits and memory ability would be strongest with the protein expressed in the synaptic pool since this pool would be enriched in receptors that are functioning in neurotransmission. We hypothesized that there would be a relationship between the $\varepsilon 2$ and $\zeta 1$ subunit expression in the synaptic pool and reference memory performance. The $\varepsilon 1$ subunit does not show significant changes in mRNA during aging and less change in protein expression than $\varepsilon 2$ and $\zeta 1[18,38,49]$, but ratios of high mRNA expression of $\varepsilon 1$ in the face of lower expression of $\varepsilon 2$ or $\zeta 1$ do show a relationship to reference memory performance [18]. It was expected that the protein expression of the $\varepsilon 1$ subunit in the synaptic pool might not change significantly with age, but might show a relationship with reference memory performance.

The present study was designed to determine whether there was a relationship between NMDA receptor subunit expression within crude synaptosomes and spatial reference memory ability in a two-day task. The main study was done with the reference task performed prior to the cued task because this most closely resembled the longer reference memory tasks that have been used previously in this lab. Additional animals from the same shipment performed the cued task first in case some previous training in the mechanics of the water maze task (e.g., getting on the platform, recognizing the platform as a means to escape) was necessary to see significant learning within 2 days in the reference memory task. A crude synaptosome preparation was used because it should be enriched in NMDA receptors that are in the synaptic pool [53]. The analysis of the protein expression of syntaxin was intended to be used as a loading control for the Western blot, but it showed significant changes during aging in the prefrontal/frontal cortex and could not be used for this purpose.

\section{Results \\ Behavioral testing - place training trials followed by cued trials}

Place trials

There was a significant overall effect of age, $F(1,12)=$ $22.785, p=.0005$, and trial, $F(15,180)=3.135, p=.0001$, on performance in place learning trials (Figure 2A, C). There was also a significant interaction between age and trial, $F(15,180)=2.408, p=.0033$, on place learning performance. The 26 months olds had significantly greater cumulative proximity measurements than 3 -month-old mice when performance was averaged across all place trials (Figure 2C). The 3 month olds showed a significant reduction in cumulative proximity between the first place trial of Day 1 and last trial of Day 2 (trial 16; $p=.0041$ ), but not between the first and eighth (last trial of Day 1) place trials $(p=.2225$; Figure 2A). The 26-month-old mice showed only a near significant decrease $(p=.0641)$ in cumulative proximity from the first to the last place trial and no significant change between place trials 1 and 8 (Day $1 ; p=.2313$; Figure $2 \mathrm{~A}$ ). There was no significant main effect of age, $F(1,12)=3.396, p=.0902$, on cumulative proximity measurements across place learning trials 1 through 8 (Day 1; Figure 2A).

\section{Probe trials}

Probe trials 0 and 1 were performed on Day 1 and Probe trial 2 on Day 2 (Figure 1). There was a significant overall effect of age, $F(1,12)=19.006, p=.0009$, and trial, $F(2$, $24)=7.154, p=.0037$, on performance in probe trials (Figure $2 \mathrm{~B}$ ). The 26 months olds $(82 \pm 3$ (SEM) tracker units) had significantly higher average proximity measurements than 3-month-old mice ( $64 \pm 3$ tracker units) when performance was averaged across all probe trials. The old mice had significantly greater average proximity measurements than young on probe trials 1 and $2(p=.02$ and .0019 , respectively), but there was no difference between the two age groups in performance on the initial probe trial $(p=.5915$; probe trial 0 ; Figure $2 \mathrm{~B})$. The 3 month olds showed a significant reduction in average proximity between probe trials 0 and $1(p=.0053)$ and probe trials 0 and $2(p=.0002$; Figure $2 \mathrm{~B})$. The 26-monthold mice showed no significant change in average proximity measurements between probe trials 0 and $1(p=.3654)$ or probe trials 0 and $2(p=.3381$; Figure 2B). There was a significant main effect of age, $F(1,12)=8.673, p=.0123$, on average proximity across probe trials 0 and 1 (Figure $2 B)$. Learning index scores were derived for each animal from the performance across the probe trials [54]. There was a significant main effect of age on learning index scores $F(1,12)=19.413, p=.0009$ with old mice having higher scores than young (Figure 2D).

\section{Cued trials}

There was no significant overall effect of age, $F(1,12)=$ $.393, p=.54$, but there was a significant overall effect of trial, $F(5,60)=15.962, p<.0001$, on performance in cued trials when they occurred after the place training trials (Figure 2E). Both the young and old mice exhibited a significant reduction ( $p=.0014$ and .0396 , respectively) in cumulative proximity measurements between the first and last cued trials (Figure 2E). There were no significant differences between the age groups in any of the individual cued trials ( $p$ range $=.0689-.75$; Figure 2E). 

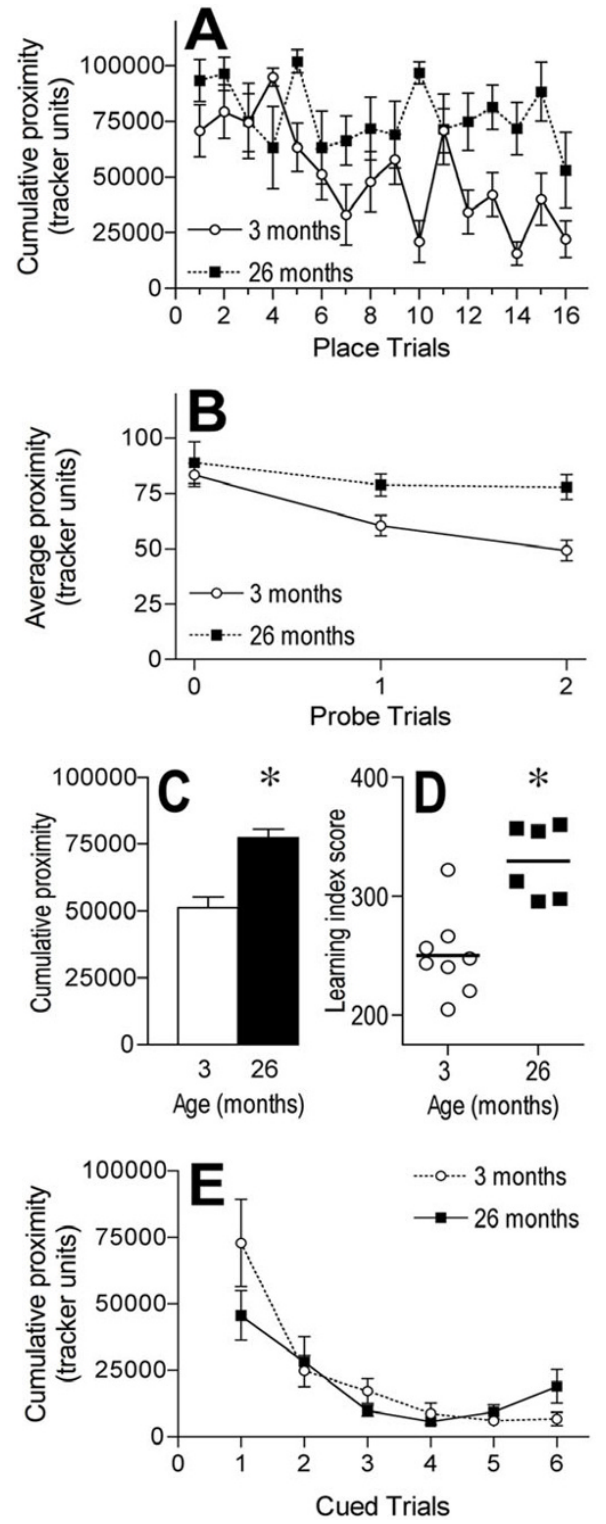

Figure 2

Effects of age on reference memory and cued tasks with cued trials conducted last. A and C: Graphs showing the performance, measured as cumulative proximity in tracker system units, of 3 and 26 month old mice within individual place learning trials $(A)$ and averaged across all place learning trials $(C)$. B: Graph showing the performance, measured as average proximity in tracker system units, of 3 and 26 month old mice within individual probe trials. D: Individual learning index scores with the horizontal bar indicating the mean for each age group. E: Graph showing the performance, measured as cumulative proximity in tracker system units, of 3 and 26 month old mice within cued trials in the water maze. $* p<.05$ for difference from 3 month old mice (analysis of variance and Fisher's protected least significant difference post-hoc analysis). $n=8$ for 3 month olds and $n=6$ for 26 month old mice. Error bars represent SEM.

\section{Behavioral testing - cued trials prior to place training trials Cued trials}

There was a significant overall effect of age, $F(1,16)=$ $5.331, p=.0346$, and there was a significant overall effect of trial, $F(5,80)=3.714, p=.0045$, on performance in cued trials when they occurred prior to the place training trials (Figure 3A). The older mice had higher cumulative proximity measurements than the young overall in the cued trials (Figure 3A). The performance averaged across cued trials 2-6 for four of the old mice was greater than 3 standard deviations from the mean of the performance of young mouse group. When these four mice were excluded from the analysis, there was no significant overall effect of age, $F(1,12)=.722, p=.41$, but there was still a significant overall effect of trial, $F(5,60)=4.437, p=.0017$, on performance in cued trials that were performed prior to the place training trials (Figure $3 \mathrm{~B}$ ).

\section{Place and probe trials following the cued trials}

There was a significant main effect of aging on performance in place trials following the cued trials, both when the four old mice that did poorly in the cued trials were excluded, $F(1,16)=57.361, p<.0001$ (Figure 3C, D), and when they were included in the analysis, $F(1,16)=$ $82.685, p<.0001$, (Figure 3D). The 26 month old mice had higher cumulative proximity measurements than the 3 month olds overall in the place trials, both when all mice were included (Figure 3D) and when the four were excluded (Figure 3C, D). The 3 month old mice did not show a significant improvement in cumulative proximity between place trials 1 and 16 (Figure 3C). There was a significant main effect of aging on performance in probe trials when place training followed the cued trials, both when the four old mice that did poorly in the cued trials were excluded, $F(1,12)=14.35, p=.0026$, and when they were included in the analysis, $F(1,16)=22.762, p=$ .0002, (not shown). The old mice had higher average proximity measurements overall in the probe trials than the younger mice (not shown).

\section{Protein expression of NMDA receptor subunits in crude synaptosomes}

Protein expression was assessed in the mice that underwent place training prior to cued training. There was a significant decrease in caudal cortex equivalents per $\mu \mathrm{g}$ of protein loaded for the $\zeta 1$ and $\varepsilon 2$ subunits of the NMDA receptor ( $p=.0014$ and .004 , respectively) in crude synaptosomes from the prefrontal/frontal cortex of 26-monthold mice as compared to young (Figure $4 \mathrm{~A}-\mathrm{C}$ ). There was no significant effect of age on caudal cortex equivalents per $\mu \mathrm{g}$ of protein loaded for the $\varepsilon 1(p=.10)$ subunit of the NMDA receptor in the prefrontal/frontal cortex (Figure $4 B, C)$. Syntaxin also showed a significant decrease in expression between 3 and 26 months of age in the prefrontal/frontal cortex $(p=.0221$; Figure $4 B, C)$. There was 

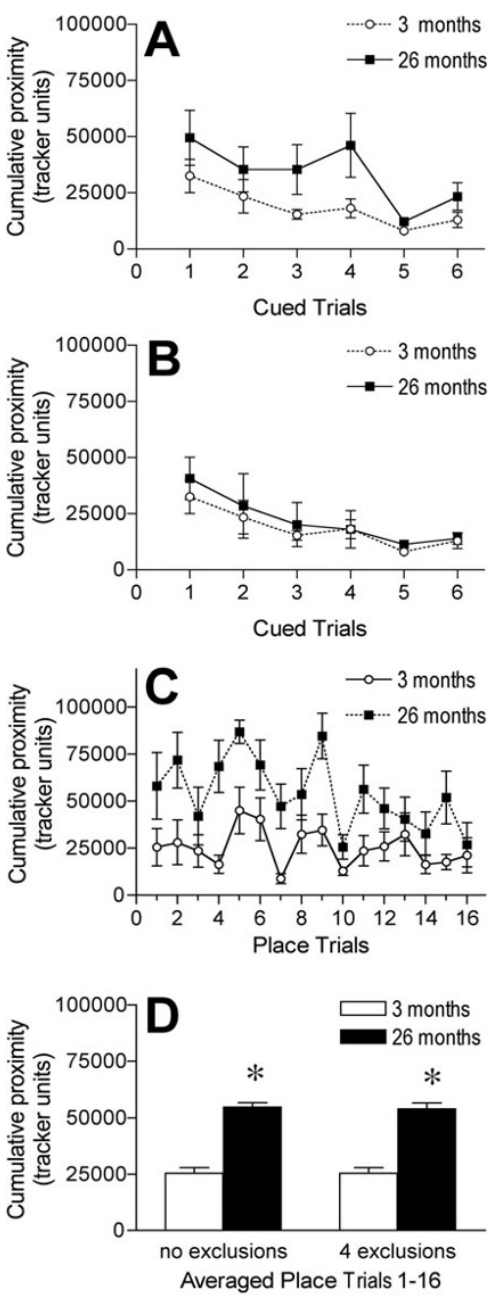

Figure 3

Effects of age on cued and reference memory tasks with cued trials conducted first. A and B: Graphs showing the performance, measured as cumulative proximity in tracker system units, of 3 and 26 month old mice within cued trials in the water maze with all animals included in analysis (A) and with 4 aged mice excluded for poorer performance on cued trials than 3 standard deviations from the mean performance in the young (B). C: Graph showing the performance, measured as cumulative proximity in tracker system units, of 3 and 26 month old mice within individual place learning trials with 4 aged mice excluded. D: Graphs showing the performance, measured as cumulative proximity in tracker system units, of 3 and 26 month old mice averaged across all place learning trials. Results are for both when all mice were included (no exclusion) and when 4 old mice were excluded ( 4 exclusions) from analysis. $* p<.05$ for difference from 3 month old mice (analysis of variance and Fisher's protected least significant difference post-hoc analysis). A and D (no exclusions): $n=8$ for 3 month olds and $n=10$ for 26 month old mice. B, C, and D (4 exclusions): $n=8$ for 3 month olds and $n=6$ for 26 month old mice. Error bars represent SEM. no significant effect of age on caudal cortex equivalents per $\mu$ g of protein loaded for the $\zeta 1(p=.5441), \varepsilon 1(p=$ $.0715)$, or $\varepsilon 2(p=.2568)$ subunits of the NMDA receptor in the hippocampus (Figure 4B, D). Syntaxin showed a near-significant increase in expression between 3 and 26 months of age in the hippocampus ( $p=.0603$; Figure $4 \mathrm{D})$.

\section{Correlations between learning performance and protein expression of NMDA receptor subunits}

There were significant negative correlations for both the overall cumulative proximity measurements in the place trials and the learning index scores derived from the probe trials and subunit equivalents/ $\mu$ g protein for the $\zeta 1$ and $\varepsilon 2$ subunits in crude synaptosomes from the prefrontal/frontal cortex when all animals were considered (Table 1 and Figure 5). The negative correlation coefficient indicated that high levels of protein expression were associated with low proximity measurements or learning index scores (i.e., good performance in the water maze). There were no significant correlations found for protein expression of the $\varepsilon 1$ subunit or syntaxin in the prefrontal/frontal cortex and performance in either the place or probe trials across the ages (Table 1). None of the subunits nor syntaxin expression levels in the hippocampus showed a significant correlation with place or probe trial performance across the ages (Table 1 ). There was a near significant correlation between the protein expression of the $\varepsilon 2$ subunit in the hippocampus of young alone $(\mathrm{R}=-757, \mathrm{p}=.086)$ and old alone $(\mathrm{R}=-77, \mathrm{p}=.077)$ and the learning index score. There was a significant correlation between syntaxin expression in the hippocampus of the old group alone and the learning index score $(\mathrm{R}=-.832, \mathrm{p}=.038)$.

\section{Discussion}

This study reports the detection of age-related changes in spatial reference memory performance in $\mathrm{C} 57 \mathrm{BL} / 6$ male mice with the use of a two-day reference memory task and changes in the protein expression of NMDA receptors within crude synaptosomes during aging. A significant decline in spatial reference learning ability in the old mice as compared to the young was detected with a two-day task, regardless of whether the cued trials were performed before or after the place training. The young mice required two days in order to show significant improvement in the place-learning task. There were significant decreases with increased age in the expression of the $\zeta 1$ and $\varepsilon 2$ subunits of the NMDA receptor in crude synaptosomes that were prepared from prefrontal/frontal cortex and these changes appeared to be related to declines in performance ability in the spatial reference memory task.

Previous work in our laboratory utilized a reference memory task in the Morris water maze that involved 12 days of testing in order to characterize learning abilities in different ages of C57BL/6 mice [17-19]. Many other studies 

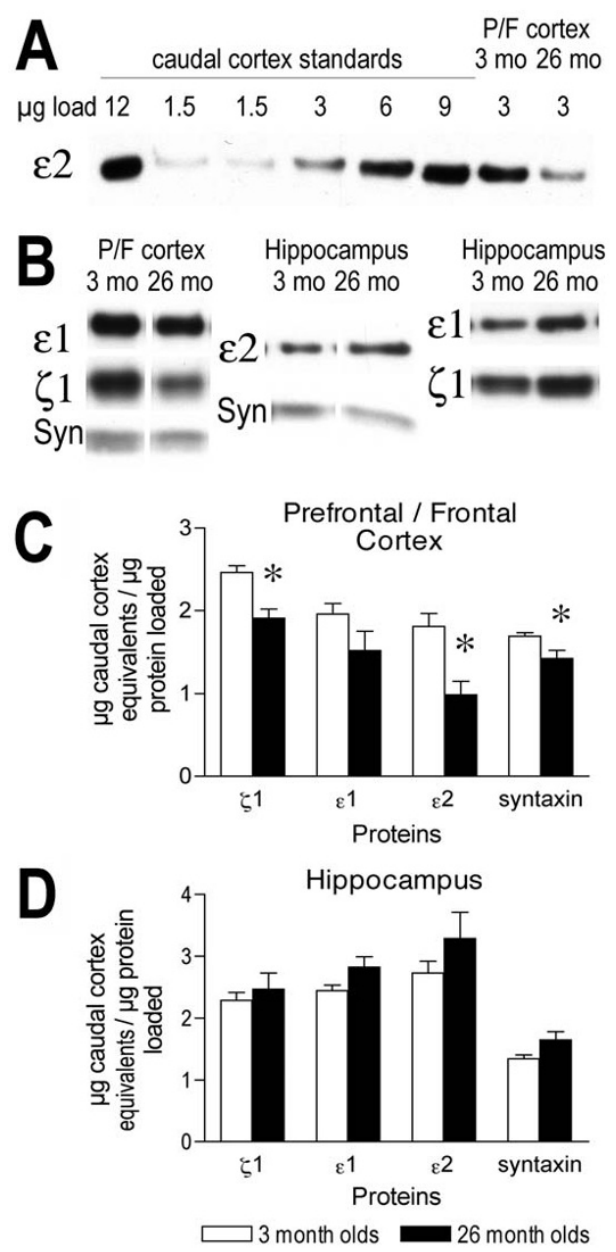

\section{Figure 4}

Effects of age on protein expression of NMDA receptor subunits in crude synaptosomes. A: Representative bands from crude synaptosomes prepared from cortex and labelled with an antibody specific for the $\varepsilon 2$ subunit. To the right are bands from different $\mu$ loads of caudal cortex used to obtain a standard curve. Five different $\mu \mathrm{g}$ amounts of caudal cortex were loaded as standards for each blot. To the left are representative bands from the prefrontal/frontal (P/F) cortex of a 3 (3 mo) and 26 (26 mo) month old mouse. B: Representative bands for all other proteins analyzed in crude synaptosomes from prefrontal/frontal cortex and hippocampus. Columns show labelling of different proteins from the same animal and well. Each well was loaded with $3 \mu \mathrm{g}$ of crude synaptosomes. C, D: Graphs of protein expression of the $\zeta I, \varepsilon I$, and $\varepsilon 2$ subunits of the NMDA receptor and syntaxin in 3 and 26 month old mice, expressed as $\mu$ g caudal cortex equivalents/ $\mu \mathrm{g}$ protein loaded, in prefrontal/frontal cortex (C) and hippocampus (D). * $p<.05$ for difference from 3 month old mice (analysis of variance and Fisher's protected least significant difference post-hoc analysis). $n=8$ for 3 month olds and $n=6$ for 26 month old mice for prefrontal/ frontal cortex. $n=6$ for both ages for hippocampus. Error bars represent SEM. showing memory declines during aging in mice report the use of between 3 and 12 days to assess reference memory ability [55-61]. Frick and colleagues have used a one-day task with 12 place trials to show significant declines in memory performance between young ( 7 months old) and middle-aged (18 months of age) male and female C57BL/ 6 mice [62]. It should be noted, however, that Calhoun and co-workers found no effect of aging on reference memory performance in male $\mathrm{C} 57 \mathrm{BL} / 6$ mice performing a reference memory task in the water maze for 5 days [63]. The present study demonstrated that declines in spatial memory ability in male C57BL/ 6 mice between 3 and 26 months of age could be detected in both place learning trials and repeated probe trials with a 2-day protocol of place training. These deficits in the reference memory task were seen in animals that showed no age-related differences in control cued testing, thus reducing the possibility that the performances in the reference memory task were due to problems with vision, motor ability or motivation. The performance of the aged animals in the 2-day task that was performed before the cued task showed tendencies in the middle to late trials to plateau at a level higher than the young performance or to show a worsening of performance. This pattern has been seen with C57BL/6 mice in a 12-day reference memory task [17-19] and in other studies using multiple training days for mice [55$57,59,61]$ and age-impaired rats [54]. Thus, this two-day task appears to be as sensitive to reference memory declines as tasks involving more days of training.

The young mice in the present study that underwent place training first showed a significant improvement in performance in probe trial performance at the end of day one as compared to the naïve probe trials, but required two days to show significant improvement in the place learning trials. The significant difference in performance between young and old mice was seen in the probe trials both during day 1 and across both days, but the age difference in place learning performance could only be detected across 2 days of training. This suggests that two days is necessary to detect the greatest differences in spatial memory ability between young and old C57BL/ 6 mice with a protocol of 8 place trials per day. Young female and male rats are able to show significant learning within eight place learning trials in a single day with the use of a similar protocol $[20,64,65]$. Our laboratory and others have also seen this necessity for using more trials for mice than rats in order to obtain significant improvement in performance in a working memory task [19,66-68]. These studies suggest that mice need more rehearsal than rats do in order to perform both reference and working memory tasks. Mice have also been shown to use different strategies to perform water maze tasks [69]. 
Table I: Pearson correlation coefficients $(R)$ for protein expression of NMDA receptor subunits in crude synaptosomes and learning performance.

\begin{tabular}{ccccc}
\hline & \multicolumn{2}{c}{ Place trial average } & Learning index score \\
\cline { 2 - 5 } Proteins & Prefrontal/Frontal Cortex & Hippocampus & Prefrontal/Frontal Cortex & Hippocampus \\
& $-.728 * *$ & +.188 & $-.658 * *$ & +.017 \\
$\varepsilon 1$ & -.286 & +.509 & -.334 & +.484 \\
$\varepsilon \mid$ & $-.594 *$ & +.306 & $-.664 * *$ & +.0003 \\
$\varepsilon 2$ & -.298 & +.442 & -.440 & +.202 \\
\hline
\end{tabular}

$* p<.05 ; * * p<.01$; Correlations include individual mice from both age groups. $\mathrm{N}=14$ (8 young \& 6 old) for Prefrontal/frontal cortex; $\mathrm{N}=12$ (6 young \& 6 old) for Hippocampus.

Some aged mice showed deficits in performance of the cued trials as compared to the young when the cued trials were performed first, but these mice improved in performance by cued trial 5 . The majority of aged mice ( 6 out of 10) that were tested in the cued trials first showed similar performances to the young mice throughout the cued trials. In previous studies, both young and old mice have also been excluded from analysis after showing poor performance in cued trials that followed place training [19]. This suggests that there are some mice that can't perform well in multiple tasks in the water maze. Regardless of whether the cued trials were conducted after or prior to the place training trials, those aged mice that showed no problems in the cued task exhibited significant deficits in the place and probe trials. This suggests that the aged mice do have problems in performing the spatial reference memory task and it is not simply a problem with learning to acquire the platform, motivation, or sensory or motor abilities. What cannot be ruled out is a problem with acquiring the specific rules for the hidden platform task.

There was a significant decline between young and old mice in the protein expression of the $\zeta 1$ and $\varepsilon 2$ subunits in crude synaptosomes from the prefrontal/frontal cortex in the present study. There was a $21 \%$ decrease in protein expression of the $\zeta 1$ subunit between 3 and 26 months of age in synaptosomes from prefrontal/frontal cortex in this study, but the protein expression of the $\zeta 1$ subunit showed a non-significant trend to decrease from 1.5 months to 25 months of age in homogenates from the caudal portion of prefrontal/frontal cortex in a previous study [52]. The protein expression of the $\varepsilon 2$ subunit also showed a greater decrease with increased age in synaptosomes from whole prefrontal/frontal cortex $(47 \%)$ than previously reported in homogenates from the caudal portion of the prefrontal/frontal cortex (17\%) [52]. These results suggest that the synaptic pool of receptors is more susceptible to the effects of aging than the whole population of receptors within the neuron in the prefrontal/frontal cortex. This may reflect an increased turnover rate in the subunits either before or after they are inserted into

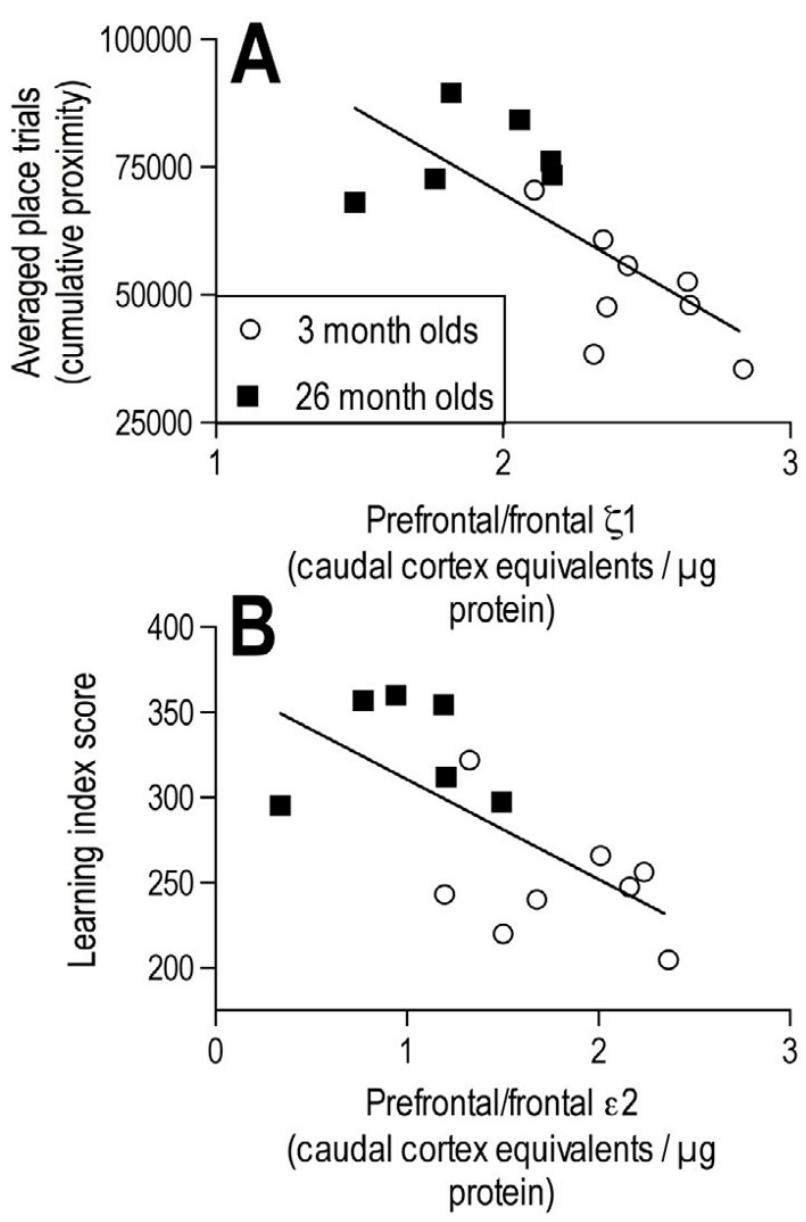

Figure 5

Relationships between reference memory performance and protein expression of NMDA receptor subunits. A, B: Correlation graphs of $\zeta I(A)$ and $\varepsilon 2$ (B) expression in the prefrontal/frontal cortex versus averaged place $(A)$ or learning index score $(B)$ derived from probe trial performance in a two-day reference memory task. Correlation coefficients are presented in Table I. Proximity measurements are given in tracker system units. 
the synaptic pool. These same subunits showed significant declines (19\% decrease for $\zeta 1$ and 21\% decrease for $\varepsilon 2$ ) between young and old mice in homogenates of the whole cerebral cortex from the same strain of mice [49]. The $\varepsilon 1$ subunit showed a significant decline between 10 and 30 months of age in homogenates from whole cerebral cortex [49], but those ages and extra cortical regions were not included in the present study.

The crude synaptosomes prepared from the hippocampus showed a trend for an increase in protein expression of the NMDA subunits examined. A similar pattern is seen in Wistar rat homogenates of hippocampus in which NR1 subunit proteins showed a significant increase and NR2A and NR2B subunit proteins showed a trend for an increase [70]. This differs, however, from the results from homogenates prepared from the hippocampi of $\mathrm{C} 57 \mathrm{BL} / 6$ mice in which the $\zeta 1$ subunit showed a significant decrease in expression between 3 and 30 months of age [49]. These differences in the effects of aging on NMDA receptor expression in the synaptic pool versus the whole tissue are similar to those found in Fisher 344 rats, in which the basal surface expression of NMDA subunit proteins does not change between adult ages [71], but expression of both NR1 $(\zeta 1)$ and NR2B $(\varepsilon 2)$ expression is decreased in homogenates of hippocampus from the same strain of rats $[50,51]$. This may represent maintenance of the synaptic pool of NMDA receptor subunits within the hippocampus during aging, but a reduction in the pool being produced. This could happen if the turnover rate at the synapse was reduced. There is also the possibility that the mice in the present study were influenced by the behavioral experience, although the rats in both of the studies mentioned above were naïve to behavioral training $[50,51]$. Regardless of the cause, there is a very different effect of aging on the NMDA subunit expression patterns between the prefrontal/frontal cortex and the hippocampus in C57BL/6 mice. It should be noted that Long-Evans rats do not show significant effects of aging on NR1 protein expression either by Western blotting of homogenates or immunofluorescence on tissue sections [72], so there appear to be some strain and species differences in the effects of aging on NMDA receptor expression in the hippocampus.

The protein expression of the $\zeta 1$ and $\varepsilon 2$ subunits in the synaptosomal fraction of the prefrontal/frontal cortex correlated negatively with the proximity measurements in the place and the learning index score derived from the probe trials. Since high proximity measurements and scores indicate poor performance, the lower expression of $\zeta 1$ and $\varepsilon 2$ in the old animals was associated with poorer performance, i.e., a positive correlation between protein and learning ability. This suggests that the changes during aging in these subunits of the NMDA receptor within the prefrontal/frontal cortex contribute to the memory problems seen in the older mice. In support of this, the administration of the $\varepsilon 2$ subunit antagonist ifenprodil into orbital regions of the prefrontal cortex of young mice inhibited learning in the same task, suggesting that $\varepsilon 2$ subunits in that region are involved in performing this spatial reference memory task [73].

The prefrontal cortex has been shown in both human and animal studies to be important in applying different strategies to the handling of memories that have spatial and temporal properties, in retrieval of the sources of information, and in adjusting to changing environmental conditions (reviewed in [3]). Lesioning studies in rats show that orbital and medial prefrontal regions contribute to performance in spatial reference memory tasks in the Morris water maze $[74,75]$. The investigators provide arguments that this is due to a deficit in organization of the behaviours necessary to perform the task or problems with handling the spatial memory temporarily, as opposed to specific spatial guidance problems [74]. Insular cortex injections of tetrodotoxin also impair the retention of platform position in the water maze [76]. More recent studies do not see an affect of lesions of the medial prefrontal cortex on performance of the spatial reference memory task in the water maze [77], but the tissue dissections in this study were not limited to medial prefrontal regions. They also included orbital and insular prefrontal regions, as well as some motor and somatosensory cortices. The literature thus provides evidence that some prefrontal regions play a role in the performance of spatial reference memory tasks. The current study suggests that declines in specific NMDA receptor subunits in the prefrontal/frontal cortex contribute to declines in performing the task by aged mice. The specific components of the performance that are affected will have to be determined.

The age-related declines seen in spatial reference memory performance of $\mathrm{C} 57 \mathrm{BL} / 6$ mice in a 12-day protocol show a relationship with decreases in binding of the transmitter glutamate to the NMDA receptor in the prefrontal/frontal cortex and hippocampus $[17,18]$ and to the ratio of $\varepsilon 1 / \zeta 1$ and $\varepsilon 1 / \varepsilon 2$ subunit mRNAs within subregions of the hippocampus [18]. Changes in NR2B protein expression in homogenates from the hippocampus also show a correlation with spatial reference memory in aged Fisher 344 rats [78]. NR1 levels in the CA3 region correlate with water maze performance during aging in Long-Evans rats [72]. There was the suggestion of a relationship between the $\varepsilon 2$ subunit expression in the hippocampus within each age group and reference memory ability, but it did not reach significance. There is a difference in how aging affects NMDA receptor binding and subunit mRNA expression between the dorsal and intermediate hippocampus in 
C57BL/6 mice [79], so using the whole hippocampus in this study may have diluted out some effects.

There was a significant decline in the protein expression of syntaxin, a presynaptic terminal membrane protein $[80,81]$, in the prefrontal/frontal cortex between 3 and 26 months of age in the C57BL/ 6 mice in this study. For this reason, syntaxin was not used to correct for loading differences in the present study. The fact that there were differences in the effects of aging on the different NMDA receptor subunit and syntaxin suggest that the effects were not due to different amounts of protein loaded. Although we were only able to control for loading differences in this study by loading known amounts of protein, the presence of the standards on every gel do provide control for variability between gels and transfers. There was no significant effect of aging on syntaxin in the hippocampus, however, to be consistent in the reporting, the hippocampal subunits were also not normalized to syntaxin. The present results are in agreement with studies on Wistar rats that also show no declines in the protein expression of syntaxin in the hippocampus [82], but differ from results of whole cerebral cortex from Wistar rats in which syntaxin showed no aging change [83]. There was evidence though in this study that syntaxin expression within the hippocampus of the old mice may contribute to the reference memory deficits seen in the aged animals.

\section{Conclusion}

Age-associated deficits in spatial reference memory were detected in C57BL/6 mice with the use of a two-day Morris water maze task. The most significant age-related declines in NMDA receptor subunit expression in these mice involved the $\varepsilon 2$ subunit within the synaptic pool of the prefrontal/frontal cortex. The $\zeta 1$ subunit also showed a significant decrease during aging in this same subfraction of prefrontal/frontal cortical tissue. Lower expression of both the $\zeta 1$ and $\varepsilon 2$ subunits across the ages was associated with poorer performance. These results suggest that changes in the synaptic pool of NMDA receptors containing $\zeta 1$ and $\varepsilon 2$ subunits within the prefrontal/frontal cortex contributed to age-related declines in performance of a spatial reference memory task.

\section{Methods \\ Subjects}

Thirty-two, male C57BL/6JNia mice (National Institute on Aging, Bethesda, MD) representing 2 different age groups ( 3 and 26 months of age) were ad libitum-fed and housed under 12/12 hour light/dark conditions for 7 days prior to and during behavioural testing. All animal procedures were approved by the Institutional Animal Care and Use Committee at Colorado State University and conformed to NIH guidelines.

\section{Behavioral testing Apparatus}

A 4 foot diameter metal tank was filled with water ( 18$20^{\circ} \mathrm{C}$ ), made opaque with non-toxic paint, to $1 \mathrm{~cm}$ above the level of the platform. The spatial clues consisted of posters and geometric figures on the walls of the room and tank and the person timing the trials. There were platform positions in the center of each quadrant and 3 positions that each differed from all other positions in their distance from the wall. One of four, approximately equidistant, entry points were randomly assigned for each trial. Trials were videotaped with a Panasonic color CCD camera and VCR and path tracings were captured and analyzed with the use of a Poly-Track Video Tracking System (San Diego Instruments) and a Zenith computer. Pretraining occurred during the 2 days prior to place training and consisted of each animal swimming for 60 seconds in the tank without the platform and then being trained to remain on a platform located in the center of the tank for 30 seconds each day. One group of mice underwent place training to assess reference memory first, followed by control cued trials to assess sensory and motor ability and motivation. This was similar to the protocol that we have used previously with longer-term reference memory tasks $[18,19]$. A separate group of mice from the same shipment experienced cued testing prior to place training.

\section{Place training trials}

A two-day task for reference memory was adapted for mice (see Figure 1) from a one-day task developed by Gallagher and co-workers [20]. Preliminary experiments showed that the mice were unable to show significant learning in one day, but could with two days of training (unpublished observation). In addition, the aged mice were not able to perform 8 training trials in a row without showing signs of fatigue or stress, so 2 blocks of 4 trials with an inter-block interval of .5 hours was used. On day 1 , mice underwent one naïve probe trial, one block of 4 place training trials with a 60 second intertrial interval in a cage between each trial, 30 minutes of cage rest, another block of 4 place training trials with a 60 second intertrial interval between each trial, 1 hour of cage rest, and a final probe trial (see Figure 1). Day 2 was the same except that there was no probe trial at the beginning of training (Figure 1). The platform remained in the same quadrant (NE) for all the place platform trials. During the place trials, the mice were placed in the tank facing the wall, and were allowed to search for the platform for 60 seconds. If they had not found it by the end of that time, they were lead to the platform. They remained on the platform for $30 \mathrm{sec}-$ onds before being removed to their cages to rest. The probe trials were designed to assess the animal's memory or spatial bias for the platform location [54]. The naïve probe trial was used to determine if there were any preexisting biases and to be able to show improvement in 
probe trial performance. The platform was not present during the probe trials and the animal was allowed to search for 30 seconds and then was removed to a cage.

\section{Cued trials}

On a separate day, after or prior to place learning, depending on the group, the cued trials were run. The platform was submerged, but was marked by an 8-inch tall support with a flag. For each animal's trial, the platform position was changed to a different quadrant. The platform locations for the cued trials were as follows: 1 - South (close to the wall), 2 - Center of tank, 3 - NE, 4 - North (half of the distance between a quadrant position and the wall), 5 - SE and 6 - NW. For each trial, the animal was placed into the tank, facing the wall at one of the entry points, and was allowed to search for the platform for 60 seconds. If the animal did not find the platform by the end of that time, they were lead to it. Each animal was tested at one platform position, then the platform was moved. This continued until all 6 positions were used. Cued trials were designed to test visual acuity, physical ability, and motivation for the task.

\section{Analysis}

Cumulative proximity was used to measure performance in the place and cued trials. Cumulative proximity was calculated by the Poly-Track system according to the method of Gallagher et al. [54], including correcting for start position. Briefly, the animal's distance from the platform, or proximity measure, was measured by the computer every frame for the duration of the animal's swim. These proximity measures were then added together to give a cumulative proximity. The Poly-Track software also corrected for start position by calculating the time to directly swim to the platform, based on swim speed and starting point and removed the data for this time period from the initial part of the record prior to calculating cumulative proximity. Average proximity to the platform was used to assess performance in the probe trials [54]. The data was collected similar to the cumulative proximity measure, but after correcting for starting point, the proximity measures were averaged [54]. Learning index scores were calculated from the probe trial data according to Gallagher et al., [54]. The mean average proximity measurements for the young mice in the naïve probe trial (probe trial 0) were divided by the mean measurements for the young mice in each separate probe trial in order to obtain a multiplier for each probe trial. The multipliers obtained were as follows: $1.00,1.38$ and 1.69 for probe trials $0-2$, respectively. For each mouse, the average proximity scores for each trial were multiplied by the respective multipliers for each trial and the products were summed to obtain a learning index score for that mouse. For both cumulative and average proximity and learning index scores, higher values represented poorer learning ability and lower values indicated better learning performance. Proximity measures were used to assess performance in these studies because they are less influenced by swim speed differences than more traditional measures such as latency to reach the platform $[17,54]$. The proximity measures are also more sensitive to some of the alternative strategies that animals can use to find the platform that may not involve place learning [54]. The learning index score provides similar information to traditional measurements of time spent in the correct quadrant, but has the added advantage of providing a single value that can represent the spatial bias in multiple probe trials and also reflect the learning curve by being weighted to reward those animals who acquire the task faster [54].

\section{Tissue dissection}

Ten days after behavioral testing, the mice were euthanized by exposure to $\mathrm{CO}_{2}$, followed by decapitation. The brains were removed, frozen on dry ice, and stored in a $70^{\circ} \mathrm{C}$ freezer. The mice that underwent reference testing prior to cued testing were used for the assessment of NMDA receptor subunit expression. This was similar to the protocol that we have used previously with longerterm reference memory tasks $[18,19]$ and there was some concern that the cued trials may have contributed to some spatial learning in the mice tested in the cued trials first. One half of the brain was warmed to $-20^{\circ} \mathrm{C}$ and placed in a plastic brain mold (Braintree Scientific, Braintree, MA) on ice and cut in the coronal plane. The rostral $3 \mathrm{~mm}$ of cortex were dissected and used for semi-quantitation of the protein expression of the $\zeta 1, \varepsilon 1$, and $\varepsilon 2$ subunits of the NMDA receptor and syntaxin by Western blotting. These prefrontal/frontal dissections included orbital, limbic, insular, cingulate, primary and association motor and sensory cortices [84]. Olfactory bulb, caudate nucleus and brainstem were dissected away from the cortex and discarded. The hippocampus was isolated, removed, and used to analyze the same proteins described above. The remaining caudal cortex (including parietal, occipital and temporal cortices) from the 3-month-old mice was used to produce standard curves for protein analysis. Brains were randomly assigned to an assay group, which consisted of multiple representatives of each age. The brains within an assay group were processed and assayed at the same time.

\section{Crude synaptosome preparation}

Crude synaptosomes (P2 fraction) from the prefrontal/ frontal cortex and hippocampus were prepared separately as described by Dunah and Standaert [53] with some modifications. The caudal cortices from the 3 month old mice were processed along with the samples of prefrontal/ frontal cortex and hippocampus and then combined prior to the protein assay for use as cortical standards. Dissected brain regions were placed in Dounce homogenizers con- 
taining ice-cold HEPES buffer (10 mM HEPES, $1 \mathrm{mM}$ EDTA, $10 \%$ sucrose, $\mathrm{pH}$ 7.4) plus a protease inhibitor cocktail ( $2 \mu \mathrm{l} / \mathrm{ml}$ buffer; Sigma, St. Louis, MO) and homogenized by hand. The homogenates were centrifuged at $1000 \times g$ for 8 minutes in an Eppendorf microcentrifuge (Brinkmann, Westbury, NY). The pellet was discarded. The supernatent was centrifuged at $9500 \times \mathrm{g}$ for 15 minutes. The supernatent was discarded and the pellet (crude synaptosomal fraction (P2)) was reconstituted in ice-cold HEPES buffer plus protease inhibitors as described above. The P2 fractions were tested for protein concentration using the bicinchoninic acid (BCA; Pierce, Rockford, IL) assay, diluted in buffer 2 to $5 \mathrm{mg} / \mathrm{ml}$ protein, aliquoted and stored at $-70^{\circ} \mathrm{C}$.

\section{Western blots}

Western blotting was performed as described by Dunah and Standaert [53]. Aliquots of the membrane preparations were thawed, diluted in $2 \%$ sodium dodecyl sulfate (SDS) and $50 \mathrm{mM}$ dithiothreitol, and boiled for $5 \mathrm{~min}$ utes. Five different amounts of protein $(1.5-12 \mu \mathrm{g})$ from the caudal cortex were loaded on each gel as standards along with 1.5-3 $\mu$ g of protein from the prefrontal/frontal region or hippocampus from each animal in one assay group. SDS-PAGE (7.5\%) gels were run in triplicate and transferred to Sequi-Blot PVDF membrane [85]. The positions of representatives for each age group were alternated across the gel. Separate gels were used for the $\varepsilon 1$ and $\varepsilon 2$ subunits because they are the same molecular weights $[45,46]$. Strips of each gel containing the appropriate molecular weight range for each protein of interest were cut and blotted separately. The membranes were blocked in 5\% Carnation nonfat dry milk in Tris-buffered saline (TBS; $20 \mathrm{mM}$ Tris-HCl, $140 \mathrm{mM} \mathrm{NaCl}, \mathrm{pH}$ 7.2) with $0.05 \%$ Tween-20 (TBS-T) for 1 hour at room temperature and were incubated overnight at $4^{\circ} \mathrm{C}$ in blocking buffer containing primary antibodies. The antibodies to identify the $\zeta 1, \varepsilon 1$, and $\varepsilon 2$ subunits of the NMDA receptor were purchased from Zymed (So. San Francisco, CA) and the syntaxin antibody was obtained from Sigma (St. Louis, MO). The membranes were rinsed 4 times for a total of 20 minutes in TBS-T, incubated in horseradish peroxidaseconjugated secondary antibody diluted in blocking buffer for 1 hour at room temperature, and rinsed 5 times for 35 minutes total in TBS-T. The membranes were then incubated in ECL SuperSignal West Pico solution (Pierce, Rockford, IL) and the bands were visualized by opposing the blots to ECL Hyperfilm.

Film images were scanned into a G4 Macintosh computer with the use of a PowerLook II scanner (UMAX, Taiwan). The integrated densities of the bands were analyzed with the use of the Gel Plotting Macro in NIH Image software. Standard curves were obtained with the use of Prism software (GraphPad Software, San Diego, CA) using a non- linear regression fit (sigmoidal dose-response (variable slope option) [86]. Sample bands were analyzed, interpolated from the standard curve and expressed as $\mu$ g cortical protein equivalents. Sample bands that had densities within the saturated portion of the standard curve were not used.

\section{Data analysis}

Statistical analysis for behavior was performed by repeated measures ANOVA (age $\times$ trial), followed by Fisher's protected LSD where applicable. The age analyses within specific trials were part of the original experimental design. Age-related differences in protein for the crude synaptosomes were analyzed by one-way ANOVA (age), followed by Fisher's protected LSD where indicated. Correlations between behavioral measurements (overall place performance and learning index score) were examined using Pearson correlation coefficients. Values of $\mathrm{p} \leq$ .05 were considered significant. All statistical analyses were performed with the use of Statview software (SAS Institute, Inc., Cary, N.C.).

\section{Abbreviations}

ANOVA analysis of variance

BCA bicinchoninic acid

CCD charged coupled device

CPP [( \pm )-2-carboxypiperazin-4-yl] propyl-1-phosphonic acid

$\varepsilon 1$ (NR2A) NMDA receptor subunit epsilon1 (2A)

$\varepsilon 2$ (NR2B) NMDA receptor subunit epsilon2 (2B)

ECL enhanced chemiluminescence

EDTA ethylenediaminetetraacetic acid

MK801 dizocilpine

mRNA messenger ribonucleic acid

NE northeast quadrant

NMDA N-methyl-D-aspartate

NW northwest quadrant

P2 crude synaptosome fraction

SDS sodium dodecyl sulfate 
SDS-PAGE sodium dodecyl sulfate - polyacrylamide gel electrophoresis

SE southeast quadrant

TBS Tris-buffered saline

TBS-T Tris-buffered saline - Tween 20

$\zeta 1$ (NR1) NMDA receptor subunit zeta1 (1)

\section{Authors' contributions}

KM conceived of the study, performed the behavioral tasks, supervised the protein work and drafted the manuscript. BS contributed to the design and discussion and performed the behavioral tasks. XZ and RH performed the protein studies. All authors read and approved the final manuscript.

\section{Acknowledgements}

This work was supported by NIH grant AGI 6322 to KM. and NIH Grant Number P20 RR 16454 from the BRIN Program of the National Center for Research Resources.

\section{References}

I. Albert MS, Funkenstein HH: The effects of age: Normal variation and its relation to disease. In Diseases of the Nervous System: Clinical Neurobiology 2nd edition. Edited by: Asbury AK, McKhann GM, McDonald WI. Philadelphia, Saunders; 1992:598-6II.

2. Gallagher M, Nicolle MM: Animal models of normal aging: Relationship between cognitive decline and markers in hippocampal circuitry. Behav Brain Res 1993, 57:155-162.

3. Gallagher M, Rapp PR: The use of animal models to study the effects of aging on cognition. Annu Rev Psychol 1997, 48:339-370.

4. Head E, Mehta R, Hartley J, Kameka M, Cummings BJ, Cotman CW, Ruehl WW, Milgram NW: Spatial learning and memory as a function of age in the dog. Behav Neurosci 1995, 109:85 I-858.

5. Zyzak DR, Otto T, Eichenbaum H, Gallagher M: Cognitive decline associated with normal aging in rats: $A$ neuropsychological approach. Learn Mem 1995, 2:1-16.

6. Barnes CA: Aging and the physiology of spatial memory. Neurobiol Aging 1988, 9:563-568.

7. Gage F, Dunnett S, Bjorklund A: Spatial learning and motor deficits in aged rats. Neurobiol Aging 1984, 5:43-48.

8. Rapp P, Rosenberg R, Gallagher M: An evaluation of spatial information processing in aged rats. Behav Neurosci 1987, 101:3-12.

9. Evans GWPD, Brennan PLMA, Skorpanich MAMA, Held DBA: Cognitive mapping and elderly adults: Verbal and location memory for urban landmarks. J Gerontol 1984, 39:452-457.

10. Cherry KE, Park DC: Individual difference and contextual variables influence spatial memory in younger and older animals. Psychol Aging 1993, 8:517-526.

II. Kirasic KC, Bernicki MR: Acquisition of spatial knowledge under conditions of temporospatial discontunity in young and elderly adults. Psychol Res 1990, 52:76-79.

12. Moore TE, Richards B, Hood J: Aging and the coding of spatial information. J Gerontol 1984, 39:210-212.

13. Sharps MJ, Gollin ES: Memory for object locations in young and elderly animals. J Gerontol I987, 42:336-341.

14. Moffat SD, Resnick SM: Effects of age on virtual environment place navigation and allocentric cognitive mapping. Behav Neurosci 2002, I 1 6:85|-859.

15. Barnes CA: Memory deficits associated with senescence: A neurophysiological and behavioral study in the rat. J Comp Physiol Psychol 1979, 93:74-104.

16. Pelleymounter MA, Smith M, Gallagher M: Spatial learning impairments in aged rats trained with a salient configuration of stimuli. Psychobiology 1987, 15:248-254.

17. Magnusson KR: Aging of glutamate receptors: Correlations between receptor binding and spatial memory performance in C57BI mice. Mech Ageing Dev 1998, 104:227-248.
18. Magnusson KR: Influence of diet restriction on NMDA receptor subunits and learning during aging. Neurobiol Aging 200I, 22:613-627.

19. Magnusson KR, Scruggs B, Aniya J, Wright KC, Ontl T, Y.Xing, Bai L: Age-related deficits in mice preforming working memory tasks in a water maze. Behav Neurosci 2003, 1 1 7:485-495.

20. Berry B, McMahan R, Gallagher M: Spatial learning and memory at defined points of the estrous cycle: Effects on performance of a hippocampal-dependent task. Behav Neurosci 1997, II I(2):267-274.

21. Cotman CW, Bridges RJ, Taube JS, Clark AS, Geddes JW, Monaghan DT: The role of the NMDA receptor in central nervous system plasticity and pathology. J NIH Res 1989, 1:65-74.

22. Magnusson KR: The aging of the NMDA receptor complex. Front Biosci 1998, 3:e70-80.

23. Alessandri B, Battig K, Welzl H: Effects of ketamine on tunnel maze and water maze performance in the rat. Behav Neural Biol 1989, 52:194-212.

24. Heale V, Harley C: MK80I and AP5 impair acquisition, but not retention, of the Morris milk maze. Pharmacol Biochem Behav 1990, 36: 145-149.

25. Mondadori C, Weiskrantz L, Buerki H, Petschke F, Fagg GE: NMDA receptor antagonists can enhance or impair learning performance in animals. Exp Brain Res 1989, 75:449-456.

26. Morris RGM, Anderson E, Lynch GS, Baudry M: Selective impairment of learning and blockade of long-term potentiation by an N-methyl-D-aspartate receptor antagonist, AP5. Nature 1986, 31 9:774-776.

27. Bashir Z, Alford S, Davies S, Randall A, Collingridge G: Long-term potentiation of NMDA receptor-mediated synaptic transmission in the hippocampus. Nature 199|, 349:156-158.

28. Harris $\mathrm{EW}$, Ganong A, Cotman $\mathrm{CW}$ : Long-term potentiation in the hippocampus involves activation in $\mathbf{N}$-methyl-D-aspartate receptors. Brain Res 1984, 323:1 32-137.

29. Artola A, Singer W: NMDA receptors and developmental plasticity in visual neocortex. In The NMDA Receptor 2nd edition edition. Edited by: Collingridge GL, Watkins JC. Oxford , Oxford University Press; 1994:313-339.

30. Pittaluga A, Fedele E, Risiglione C, Raiteri M: Age-related decrease of the NMDA receptor-mediated noradrenaline release in rat hippocampus and partial restoration by D-cycloserine. Eur J Pharm 1993, 23 I ( I): 129-134.

31. Gonzales RA, Brown LM, Jones TW, Trent RD, Westbrook SL, Leslie SW: N-methyl-D-aspartate mediated responses decrease with age in Fischer 344 rat brain. Neurobiol Aging 1991, 1 2:219-225

32. Barnes CA, McNaughton BL: An age comparison of the rates of acquisition and forgetting of spatial information in relation to long-term enhancement of hippocampal synapses. Behav Neurosci 1985, 99: 1040-1048.

33. Deupree DL, Bradley J, Turner DA: Age-related alterations in potentiation in the CAI region in F344 rats. Neurobiol Aging 1993, 14:249-258.

34. Wenk GL, Walker LC, Price DL, Cork LC: Loss of NMDA, but not GABA-A, binding in the brains of aged rats and monkeys. Neurobiol Aging 1991, I 2:93-98.

35. Tamaru M, Yoneda Y, Ogita K, Shimizu J, Nagata Y: Age-related decreases of the $\mathrm{N}$-methyl-D-aspartate receptor complex in the rat cerebral cortex and hippocampus. Brain Res 1991, 542:83-90.

36. Kito S, Miyoshi R, Nomoto T: Influence of age on NMDA receptor complex in rat brain studied in in vitro autoradiography. J Histochem Cytochem 1990, 38:1725-1731.

37. Pelleymounter MA, Beatty G, Gallagher M: Hippocampal 3H-CPP binding and spatial learning deficits in aged rats. Psychobiology 1990, 18:298-304.

38. Magnusson KR: Declines in mRNA expression of different subunits may account for differential effects of aging on agonist and antagonist binding to the NMDA receptor. J Neurosci 2000 , 20:1666-1674.

39. Magnusson KR, Scanga C, Wagner AE, Dunlop C: Changes in anesthetic sensitivity and glutamate receptors in the aging canine brain. J Gerontol: Biol Sci 2000, 55(9):B448-B454.

40. Piggott MA, Perry EK, Perry RH, Court JA: [3H]MK-80I binding to the NMDA receptor complex, and its modulation in human frontal cortex during development and aging. Brain Res 1992, 588:277-286.

41. Moriyoshi K, Masu M, Ishii T, Shigemoto R, Mizuno N, Nakanishi S: Molecular cloning and characterization of the rat NMDA receptor. Nature 1991, 354:31-37.

42. Ishii T, Moriyoshi K, Sugihara H, Sakurada K, Kadotani H, Yokoi M, Akazawa C, Shigemoto R, Mizuno N, Masu M, Nakanishi S: Molecular 
characterization of the family of the $\mathbf{N}$-methyl-D-aspartate receptor subunits. J Biol Chem 1993, 268(4):2836-2843.

43. Monyer H, Sprengel R, Schoepfer R, Herb A, Higuchi M, Lomeli H, Burnashev N, Sakmann B, Seeburg PH: Heteromeric NMDA receptors: Molecular and functional distinction of subtypes. Science 1992, 256:1217-1221.

44. Ikeda K, Nagasawa M, Mori H, Araki K, Sakimura K, Watanabe M, Inoue $Y$, Mishina $M$ : Cloning and expression of the e4 subunit of the NMDA receptor channel. FEBS Lett 1992, 313:34-38

45. Kutsuwada T, Kashiwabuchi N, Mori H, Sakimura K, Kushiya E, Araki K, Meguro H, Masaki H, Kumanishi T, Arakawa M, Mishina M: Molecular diversity of the NMDA receptor channel. Nature 1992, 358:36-4I

46. Meguro H, Mori H, Araki K, Kushiya E, Kutsuwada T, Yamazaki M, Kumnainshi T, Arakawa M, Sakimura K, Mishina M: Functional characterization of a heteromeric NMDA receptor channel expressed from cloned cDNAs. Nature 1992, 357:70-74.

47. Yamazaki M, Mori H, Araki K, Mori KJ, Mishina M: Cloning, expression and modulation of a mouse NMDA receptor subunit. FEBS Lett 1992, 300(I):39-45.

48. Nakanishi S: Molecular diversity of glutamate receptors and implications for brain function. Science 1992, 258:597-603

49. Magnusson KR, Nelson SE, Young AB: Age-related changes in the protein expression of subunits of the NMDA receptor. $\mathrm{Mol}$ Brain Res 2002, 99:40-45.

50. Clayton DA, Browning MD: Deficits in the expression of the NR2B subunit in the hippocampus of aged Fisher 344 rats. Neurobiol Aging 2001, 22:165-168.

51. Eckles-Smith K, Clayton D, Bickford P, Browning MD: Caloric restriction prevents age-related deficits in LTP and in NMDA receptor expression. Mol Brain Res 2000, 78:154-162.

52. Ontl T, Xing Y, Bai L, Kennedy E, Nelson S, Wakeman M, Magnusson $K R$ : Development and aging of $\mathrm{N}$-methyl-D-aspartate receptor expression in the prefrontal / frontal cortex of mice. Neuroscience 2004, 123:467-479.

53. Dunah AW, Standaert DG: Dopamine DI receptor-dependent trafficking of striatal NMDA glutamate receptors to the postsynaptic membrane. J Neurosci 200I, 2 I:5546-5558.

54. Gallagher M, Burwell R, Burchinal M: Severity of spatial learning impairment in aging: Development of a learning index for performance in the Morris water maze. Behav Neurosci 1993 107:618-626

55. Buhot MC, Wolff M, Savova M, Malleret G, Hen R, Segu L: Protective effect of 5-HTIB receptor gene deletion on the age-related decline in spatial learning abilities in mice. Behav Brain Res 2003 I 42: $135-142$.

56. Forster MJ, Dubey A, Dawson KM, Stutts WA, Lal H, Sohal RS: Agerelated losses of cognitive funciton and motor skills in mice are associated with oxidative protein damage in the brain. Proc Natl Acad Sci USA 1996, 93:4765-4769.

57. Frick KM, Burlingame LA, Arter JA, Berger-Sweeney J: Reference memory, anxiety and estrous cyclicity in C57BL/6NIA mice are affected by age and sex. Neuroscience 2000, 95(I):293-307.

58. Frick KM, Fernandez SM: Enrichment enhances spatial memory and increases synaptophysin levels in aged female mice. Neurobiol Aging 2003, 24:615-626.

59. Haroutunian V, Zhou Y, Elder G, Li C, Lazzarini RA: Age-dependent spatial memory deficits in transgenic mice expressing the human mid-sized neurofilament gene: I. Mol Brain Res 1996, 42:62-70.

60. Trinchese F, Liu S, Battaglia F, Walter S, Mathews PM, Arancio O. Progressive age-related development of Alzheimer-like pathology in APP/PSI mice. Ann Neurol 2004, 55:80I-8I4.

61. van Praag H, Shubert T, Zhao C, Gage FH: Exercise enhances learning and hippocampal neurogenesis in aged mice. I Neurosci 2005, 25:8680-8685.

62. Frick KM, Stearns NA, Pan JY, Berger-Sweeney J: Effects of environmental enrichment on spatial memory and neurochemistry in middle-aged mice. Learn Mem 2003, 10:187-198.

63. Calhoun ME, Kurth D, Phinney AL, Long JM, Hengemihle JM, Mouton $P R$, Ingram DK, Jucker M: Hippocampal neuron and synaptophysin-positive bouton number in aging C57BL/6 mice. Neurobiol Aging 1998, 19:599-606.

64. Packard MG: Posttraining estrogen and memory modulation. Hormones Behav 1998, 34:126-139.

65. Packard MG, Teather LA: Posttraining estradial injections enhance memory in ovariectomized rats: cholinergic blockade and synergism. Neurobiol Learn Mem 1997, 68:172-188.

66. Means LW, Fernandez T): Daily glucose injections facilitate performance of a win-stay water-escape working memory task in mice. Behav Neurosci 1992, 106:345-350.
67. Whishaw IQ: A comparison of rats and mice in a swimming pool place task and matching to place task: some surprising differences. Physiol Behav 1995, 58:687-693.

68. Whishaw IQ: Accelerated nervous system development contributes to behavioral efficiency in the laboratory mouse: A behavioral review and theoretical proposal. Dev Psychobiol 200I, 39:15I-170

69. Frick KM, Stillner ET, Berger-Sweeney J: Mice are not little rats: species differences in a one-day water maze task. Learn Mem 2000, I I( I6):346I-3465.

70. Monti B, Virgili M, Contestabile A: Alterations of markers related to synaptic function in aging rat brain, in normal conditions or under conditions of long-term dietary manipulation. Neurochem Int 2004, 44:579-584.

71. Clayton DA, Grosshans DR, Browning MD: Aging and surface expression of hippocampal NMDA receptors. J Biol Chem 2002, 277:14367-14369.

72. Adams MM, Smith TD, Moga D, Gallagher M, Wang Y, Wolfe BB, Rapp $\mathrm{PR}$, Morrison JH: Hippocampal dependent learning ability correlates with $\mathrm{N}$-methyl-D-aspartate (NMDA) receptor levels in CA3 neurons of young and aged rats. J comp Neurol 200I, 432:230-243

73. Magnusson KR, Thatcher-Mason S, Rehard J, Scruggs B: Antagonism of e2 (NR2B) subunit-containing NMDA receptors impaired young mice \& enhanced aged mice performing in a spatial memory task. Soc Neurosci Abstr 2006, 273:16.

74. Kolb B, Buhrmann K, McDonald R, Sutherland RJ: Dissociation of the medial prefrontal, posterior parietal, and posterior temporal cortex for spatial navigation and recognition memory in the rat. Cereb Cortex 1994, 6:664-680.

75. Kolb B, Sutherland RJ, Whishaw IQ: A comparison of the contributions of the frontal and parietal association cortex to spatial localization in rats. Behav Neurosci I 983, 97(I): 13-27.

76. Bermudez-Rattoni F, Introini-Collison IB, McGaugh JL: Reversible inactivation of the insular cortex by tetrodotoxin produces retrograde and anterograde amnesia for inhibitory avoidance and spatial learning. Proc Natl Acad Sci USA 1991, 88:5379-5382.

77. Sloan HL, Good M, Dunnett SB: Double dissociation between hippocampal and prefrontal lesions on an operant delayed matching task and a water maze reference memory task. Behav Brain Res 2006, I71:116-126.

78. Clayton DA, Mesches MH, Alvarez E, Bickford PC, Browning MD: A hippocampal NR2B deficit can mimic age-related changes in long-term potentiation and spatial learning in the Fischer 344 rat. J Neurosci 2002, 22:3628-3637.

79. Magnusson KR, Kresge D, Supon J: Differential effects of aging on NMDA receptors in the intermediate versus the dorsal hippocampus. Neurobiol Aging 2006, 27:324-333.

80. Yoshida A, Oho C, Omori A, Kuwahara R, Ito T, Takahashi M: HPC$I$ is associated with synaptotagmin and omega-conotoxin receptor. J Biol Chem 1992, 267(35):24925-24928.

8I. Bennett MK, Calakos N, Scheller RH: Syntaxin, a synaptic protein implicated in docking of synaptic vesicles at presynaptic active zones. Science 1992, 257:255-259.

82. Iwamoto M, Hagishita T, Shoji-Kasai Y, Ando S, Tanaka Y: Agerelated changes in the levels of voltage-dependent calcium channels and other synaptic proteins in rat brain cortices. Neurosci Lett 2004, 366:277-281.

83. Shimohama S, Fujimoto S, Sumida Y, Akagawa K, Shirao T, Matsuoka $Y$, Taniguchi T: Differential expression of rat brain synaptic proteins in development and aging. Biochem Biophys Res Comm 1998, 25I:394-398.

84. Franklin KBJ, Paxinos G: The Mouse Brain in Stereotaxic Coordinates. San Diego, Academic Press; 1997: II2.

85. Towbin H, Staehelin T, Gordon J: Electrophoretic transfer of proteins from polyacrylamide gels to nitrocellulose sheets: Procedure and some applications. Proc Natl Acad Sci USA 1979 , 76:4350-4354.

86. Wang YH, Bosy TZ, Ysauda RP, Grayson DR, Vicini S, Pizzorusso T, Wolfe BB: Characterization of NMDA receptor subunit-specific antibodies: Distribution of NR2A and NR2B receptor subunits in rat brain and ontogenic profile in the cerebellum. J Neurochem 1995, 65:176-183. 